\title{
WACANA HIPERREALITAS DALAM FILM BERGENRE FANTASI
}

\author{
Arwin Purnama Jati \\ Dosen Program Studi Desain Komunikasi Visual \\ Fakultas Arsitektur dan Desain, \\ Universitas Katolik Soegijapranata Semarang \\ E-mail: arwinpj82@yahoo.com
}

\section{ABSTRACT}

Global culture and industrial society have been raise production and consumption habits. The discourse is related to the role of media as a culture-mass product. Film with fantasy genre is part of culture-mass product which has influenced the society significantly. Media is formed by narration and visual signs which creates social habits pattern. Fantasy films as itself reconstruct the audience's mind, accommodate idea and imagination of life and its social relations.

As it is formed in mind of the audience, imagination represents the need of "new-world" realities that is virtual means, which is produced as a consequence of digital revolution and technology product that are both related to the necessity of production. In this case, there is continuity production of visual signs, therefore treats to the rise of "hiperreality" by its product, that is fantasy-film as a discourse.

\section{Keywords: Hyperreality, Film, Virtual, Fantasy}

\section{Pendahuluan}

Aspek visual merupakan aspek yang tak terpisahkan dalam ranah kajian desain komunikasi visual. Perkembangan teknologi informasi serta komunikasi yang diwarnai dengan dinamika digitalisasi dalam budaya visual ikut mempengaruhi budaya konsumsi masyarakat terhadap produk visual. Film sebagai bagian dari produk visual berperan penting dalam membentuk perilaku sosial. Film mencakup produksi visual yang secara impresif mampu menarik minat bahkan mempengaruhi persepsi masyarakat terhadap wacana yang sedang terjadi dalam ranah sosial. Film bahkan mampu menciptakan citra yang ditangkap sebagai realitas di "dunia kedua" yang diciptakan untuk memberi bayangan atas harapan masyarakat tentang zaman yang diharapkan lebih baik dari situasi zaman saat ini. Film secara spesifik mampu merepresentasikan realitas semu yang diwujudkan melalui tandatanda visual (ikonik, simbolik) yang dipersepsikan secara hegemonis oleh masyarakat sebagai citraan yang sesungguhnya.

Perkembangan teknologi dalam dunia desain telah menghadirkan inovasi digital dalam membentuk citra (image) visual yang mendekati realitasnya.Teknologi CGI (Computer Generated Imagery) yang digunakan dalam animasi merupakan teknis bidang computer grafis yang mampu menghasilkan visual-effect untuk mengontrol dan menyempurnakan penciptaan gambar dalam proses produksi film. Teknis CGImaupun kombinasi live actionyang seringkali digunakan untuk menggabungkan "wujud riil" dengan "wujud rekaan" (fiksi-imajinatif) menjadi salah satu media yang memuaskan imajinasi audiens tentang fantasi dunia baru.Teknologi ini mampu menciptakan simulasi-simulasi imajinasi melalui kreativitas visual dan memunculkan citracitra tertentu yang tidak dapat terpenuhi dalam realitas, yang seringkali merupakan pencitraan visual atas imajinasi yang melampaui realitas. Inovasi dalam bidang grafis komputer tersebut dikatakan sebagai bagian dari revolusi digital yang mendukung peran media dalam menyampaikan pesan dan makna kepada audiens. Produksi film dengan sentuhan teknologi CGI terutama 
memberikan solusi atas perwujudan imajinasi atas sesuatu yang tidak konkret, memberikan kesempatan untuk menciptakan suatu "bentuk khayal" yang diperlukan dalam membuka ruang fantasi dalam benak audiens.

Pencitraan dan Digitalisasi dalam Film Bergenre Fantasi

Fantasi sebagai kata kunci digunakan untuk mengkategorikan film dengan tema-tema di luar kenyataan atau khayalan. Fantasi menurut ilmu Psikologi dikatakan sebagai suatu bentuk gejala pengenalan (kognisi) dimana seseorang memunculkan khayalan-khayalan, membentuk daya imajinasi dan menghasilkan sesuatu yang baru dalam benak. Sedangkan film ber-genre fantasi merupakan kategori film dengan kecenderungan muatan elemen imajinasi yang menjadi basis tema sebagian besar atau keseluruhan film tersebut, pada umumnya dikombinasikan dengan teknis animasi ataupun keseluruhan berupa animasi.

Film fantasi terutama science-fiction (scifi) memiliki karakter tema maupun visual yang merepresentasikan hasil imajinasi manusia yang dianalogikan melalui media sains dan teknologi, ber-setting futuristik, berkaitan dengan penemuan teknologi seperti robot maupun dimensi ruang dan waktu yang berbeda dengan dunia nyata (bumi). Duplikat realitas melalui media tersebut dipersepsikan sebagai realitas sebenarnya, melampaui batas realitasnya, yang dikatakan Jean Baudrillard (1981) sebagai hyperreality (hiperrealitas).

\section{Hiperrealitas dalam Film Fantasi yang Mengabstraksi Realitas}

Film dengan genre fantasisci-fi, sebagai contoh "Avatar" (dirilis tahun 2009, produksi Twentieth Century Fox), dengan setting futuristik, menceritakan sebuah planet bernama Pandora yang dihuni "alien" dengan spesies berbeda dari manusia secara fisik (berkulit biru, bertaring, skala tubuh yang berbeda, dan sebagainya), demikian juga binatang yang ada di planet tersebut, juga vegetasi yang tidak pernah dijumpai di bumi.

Secara tematis, film ini berusaha menghadirkan kehidupan yang ada diluar bumi,

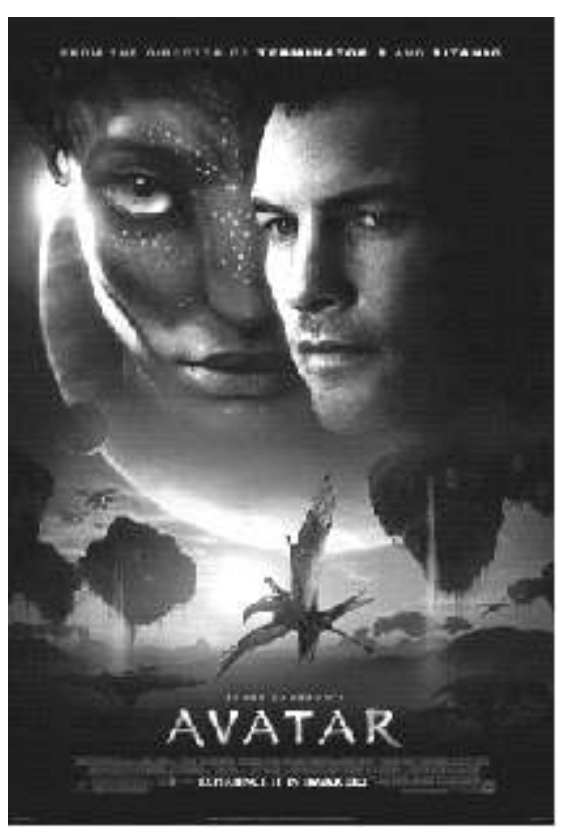

Poster film Avatar yang menampilkan citraan realitas melalui diferensiasi dimensi ruang dan waktu (Sumber: www.IMBd.com) 
dirasionalisasi serta dipelajari secara ilmiah dengan nuansa cyberculture yang kuat. Dari aspek visual, film ini memanjakan indera penglihatan melalui kombinasi citraan animasi dengan realitas, terutama pada settingplanet yang dihuni bangsa Pandora. Iluminasi dan warna berperan penting didalam film ini untuk menghadirkan suasana fantasi yang impresif. Dalam hal ini, aspek visual berperan menciptakan batas antara dunia nyata dengan dunia khayal . Film ini menjadi media untuk menghadirkan representasi imajinasi yang dimiliki manusia secara visual. Dilihat dari kacamata sosial, film ini merefleksikan apa yang ada di dunia nyata, kehidupan komunal, interaksi, alam, kepercayaan (belief), dan sistem sosial, yang diwujudkan melalui tanda-tanda tertentu. Tanda mewakili ikon yang didasarkan pada "keserupaan" yang berelasi atau mengacu pada objek yang sebenarnya (Budiman, 2011: 69 - 70). Namun setting dan visualisasi seakan-akan menyajikan suatu bentuk imajinatif yang dianggap khayal, misalnya binatang berkaki enam dan bermata empat, bunga yang bercahaya, bangsa Pandora yang bertaring dan memiliki ekor serta berkulit biru.

Citra semacam ini tidak kita jumpai dalam kehidupan nyata, sehingga film tersebut membuat rasionalisasi dengan menempelkan identitas "planet Pandora" sebagai setting tempat, yang dapat dijangkau melalui kuasa teknologi dan ilmu pengetahuan. Dengan kata lain, merasionalisasi hal-hal irrasional kedalam realitas, dan dimediasi oleh persepsi mengenaikuasa ilmu pengetahuan serta visualisasi ikonik yang dapat diterima sebagai 'citra baru'. Realitas rekaan dalam film tersebut seakan-akan mampu melampaui realitas dan membuai audiens sehingga menangkap visualisasi dalam film sebagai hal yang sesungguhnya, yaitu diterima sebagai realitas kehidupan yang sesungguhnya (hiperrealitas). Kombinasi antara persepsi, latarbelakang pengalaman dan pengetahuan, serta rasionalisasi melalui kehadiran kuasa ilmu pengetahuan dan teknologi diterima oleh audiens sebagai realitas, dan dihadirkan melalui aspek visual yang mampu menciptakan impresi serta mengakomodasi khayalan (angan-angan) yang memuaskan alam pikir audiens.Film menjadi salah satu produk industri kebudayaan yang dikonsumsi secara terus-menerus dalam masyarakat modern karena kebutuhan melakukan pencarian yang irasional yang didominasi oleh rasionalitas teknologi (Adorno dalam Scott, 2012: 305).

Kehadiran aspek visual melalui modelmodel fantasi (dalam film) dianggap merupakan bagian reproduksi simulasi yang menurut Piliang (2010: 199 - 201) dapat melenyapkan realitas. Simulasi yang mengacu pada konsep simulacra yang dicetuskan oleh Jean Baudrillard mengungkap tentang konversi 'ruang' dari abstrak ke konkret, atau sebaliknya dari konkret ke abstrak, seperti halnya dalam film fantasi membuat khayalan (yang abstrak) seakan-akan menjadi konkret, sementara medianya (film bioskop atau televisi) mengabstrakkan hal konkret, yaitu kehidupan yang ditonton dan dimampatkan kedalam 'layar sempit'. Hiperrealitas mengakomodasi imajinasi dan mengarahkan pada tindakan konsumsi yang berkelanjutan pada audiens. Masyarakat konsumer dalam kehidupan pasca modernitas membutuhkan produksi secara terus-menerus, termasuk mengkonsumsi tanda dan kebahasaan yang telah diciptakan akibat pemenuhan kebutuhan konsumsi masal oleh media, termasuk media film fantasi yang merefleksikan abstraksi realitas tersebut.

Bahasa dalam film yang memuat kode dan 
tanda tertentu berfungsi sebagai sistem representasional yang terwujud secara simbolik (Hall, 1997:1). Simbol-simbol kebahasaan tersebut dapat berupa ikon maupun tanda-tanda visual lainnya, yang bisa dimaknai secara lugas maupun interpretif. Teknologi telah membawa kebudayaan pada realitas citraan dalam media, yang diciptakan melalui semiotika tanda (penanda dan petanda) dan menghasilkan makna tertentu. Tanda-tanda dapat berupa aspek visual seperti halnya dalam film fantasi yang merupakan sarana mengkomunikasikan makna kepada audiens. Makna yang tertangkap oleh perspektif audiens tidak menjadi mutlak dan dapat menjadi variatif.

Hal ini dipengaruhi oleh persepsi, pengalaman empiris berikut nilai-nilai yang terjadi dalam setiap individu yang menontonnya. Film bergenre fantasi-superhero misalnya, yaitu "Iron Man” (dirilis tahun 2008, produksi Paramount Pictures), yang menghadirkan nuansa futuristik dan fiksi-ilmiah tidak semata-mata ditangkap sebagai film dengan wacana tunggal tentang penyelamatan manusia dan dunia. Aspek visual yang diproduksi dalam film ini mampu menghantarkan simulasi kecanggihan teknologi dengan bantuan teknis animasi digital (yang juga bagian dari teknologi itu sendiri). Audiens dihanyutkan dengan visualisasi 'magis' teknologi yang pada dasarnya merupakan rekaan. Namun, tanda-tanda visual dan simbolik dalam film, misalnya energi dan hologram ditunjukkan melalui mekanisme sinar yang dihasilkan melalui proses animasi mampu mengakomodasi khayalan audiens tentang energi dan holografi dalam citra yang dianggap nyata. Wacana lain tentang "impian teknologi masa depan" diciptakan dalam film ini untuk memuaskan angan-angan audiens, sehingga secara dapat berakibat pada meningkatnya kebutuhan konsumsi terhadap film fantasi tersebut.

Ketika kebutuhan konsumsi meningkat, maka kebutuhan produksi atas film pun bertambah. Disinilah produksi tanda visual semakin berlebih untuk memenuhi bahkan melampaui batas pemenuhan fantasi audiens, yang berakibat peningkatan abstraksi terhadap realitas. Di sisi lain, teknologi animasi dianggap sebagai media perantara untuk menciptakan tanda-tanda visual tersebut sebagai abstraksi visual. Sebagai contoh, baju besi robotik tokoh Iron Man yang dibuat melalui digitalisasi dianggap sebagai materi logam besi yang sesungguhnya, dengan dukungan audio yang mencitrakan bunyi logam yang digesekkan atau dibenturkan. Sehingga, penandaan tersebut bersifat referensial, yaitu mengacu pada wacana dasar penciptaan tanda visual kedalam film.

Selain itu, hiperrealitas juga terjadi di film animasi "Tron Legacy" (dirilis tahun 2010, produksi Walt Disney Pictures), film bernuansa fiksi-ilmiah yang mengangkat tema tentang penciptaan kode-kode digital untuk membangun "dunia virtual-game". Film ini lebih merepresentasikan penciptaan dimensi baru melalui aspek digital, yang mencoba mengasumsikan kemungkinan-kemungkinan yang terjadi akibat revolusi dunia digital. Di sisi lain, secara tematis film ini menghadirkan wacana tentang kejenuhan pada realitas sehingga memunculkan imej mengenai suatu ruang dan waktu yang memiliki sistemnya sendiri yang terpisah dari realitas dan berupaya mencapai suatu kesempurnaan yang dibutuhkan peradaban. Aspek hiperrealitas dimunculkan melalui imej visual peradaban futuristik dalam skala kecil namun dengan sistem yang lebih rapi dan futuristik. Secara metaforis, simbol-simbol visual kota futuristik dan sistem sosial yang direpresentasikan 


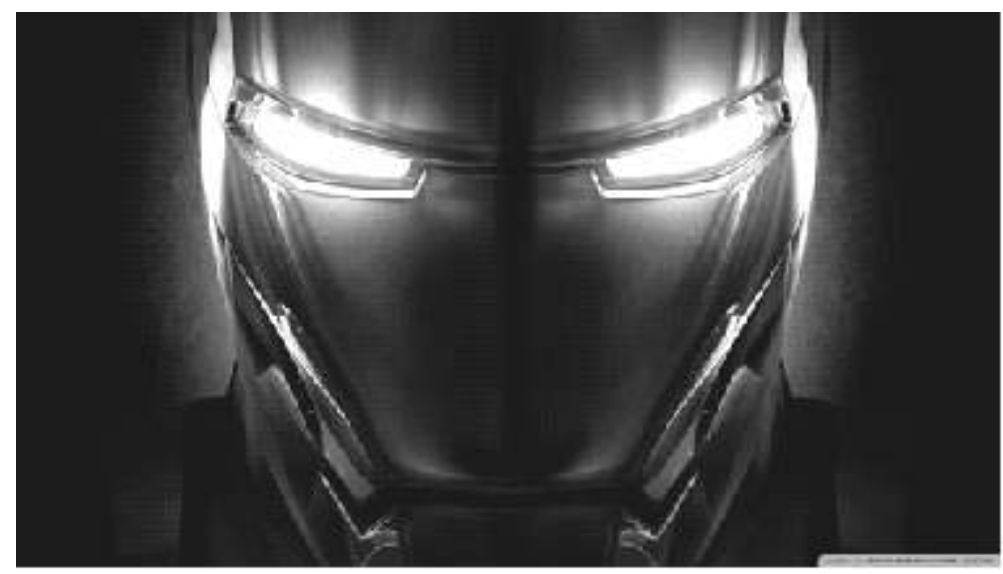

Visualisasi karakter robotik Iron Man Sumber: www.popmythology.com
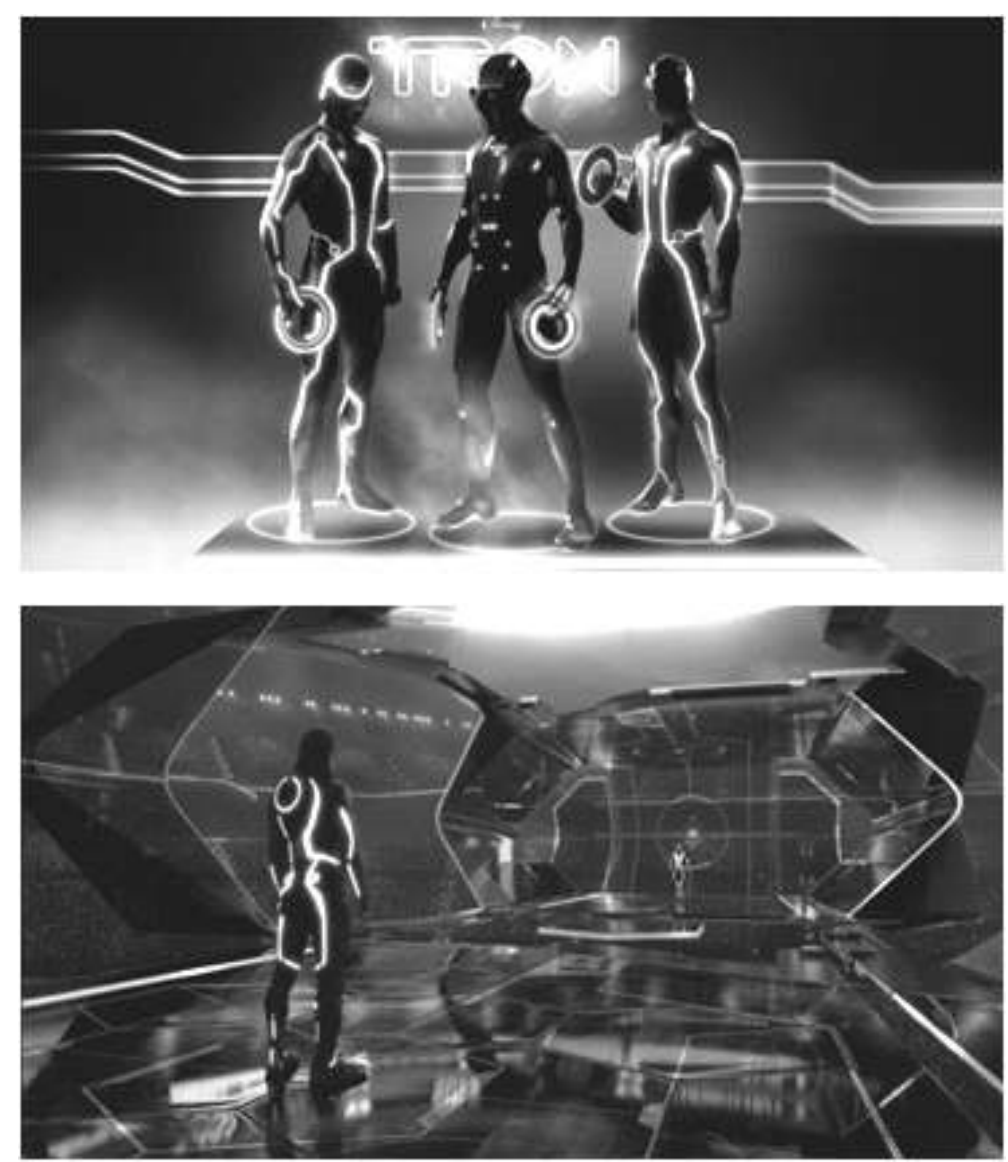

Visualisasi karakter dan setting sistem peradaban film Tron Legacy Sumber: (kiri) www.wall.alphacoders.com dan (kanan) www.fanpop.com

dalam film menghadirkan makna "harapan" atas realitas saat ini yang dianggap masih memiliki banyak kekurangan.

Lapisan makna dalam hal ini menurut Barthes (1990:41) termasuk dalam kategori lapisan informasional, yaitu makna yang dapat diambil dari aspek visual meliputi setting, kostum, tata letak, karakter, dan sebagainya yang merupakan semiotika tingkat pertama (mengandung pesan dalam kaitannya dengan komunikasi). Rasionalisasi muncul dalam muatan teknologi yang dianggap memiliki kuasa dan 
kesempatan mengubah zaman atau peradaban. Bahkan teknologi dianggap memiliki kuasa atas teknologi itu sendiri. Gagasan-gagasan ilmu pengetahuan baik dalam dunia teknologi informasi, digital, cloning, maupun dehumanisasi dipaparkan melalui kemasan tokoh dan situasi virtual. Audiens seakan digiring untuk meyakini kebenaran ilmiah yang dihadapkan pada persoalan-persoalan khusus seperti sosial dan politik, yang identik dengan produk modernitas.

\section{Penutup}

Produksi tanda melalui aspek visual mengarahkan imajinasi yang abstrak tidak sematamata diterima sebagai satu faktor yang mempengaruhi persepsi audiens mengenai realitas. Faktor digitalisasi (revolusi digital) yang berada dalam otorisasi produsen turut mendukung pencitraan yang menunjang aspek hiperrealitas sampai ke target audiens. Faktor digitalisasi secara tidak langsung menentukan bagaimana suatu makna tanda akan diterima sebagai realitas, karena mekanisme digital mampu menciptakan 'realitas semu'yang bahkan dapat mempengaruhi audiens secara emosional dan menciptakan kebutuhan berkelanjutan untuk mengkonsumsi film sebagai produk budaya massa. Fantasi yang diciptakan melalui produksi tanda visual dalam film mengupayakan bertemunya gagasan-gagasan imajinatif tentang realitas diluar realitas. Contoh film fantasi Avatar, Iron Man, dan Tron Legacy mewakili aspek-aspek penandaan yang berada dalam lingkup penyajian hiperrrealitas yang serupa, yaitu rasionalisasi melalui ilmu pengetahuan dan teknologi. Diferensiasi yang terbentuk berupa gagasan mengenai setting dan kepentingan-kepentingan tertentu sebagai alasan diproduksinya film-film tersebut. Kekuasaan teknologi melalui tampilan citra cyberculture, penyelamatan ekologis melalui dimensi baru, hadirnya sosok 'penyelamat kehidupan', dan digitalisasi peradaban. Penumbuhan hiperrealitas dalam film-film tersebut didukung dengan fantasifantasi baru kehidupan yang diasumsikan terjadi di kehidupan masa depan, yang membawa harapan penyempurnaan peradaban masa kini. Pada akhirnya produksi tanda yang terus-menerus dan bertambah turut membangun hiperrealitas dalam media film terkait dengan kebutuhan konsumsi masal atas tanda, dimana tanda-tanda tersebut secara kontinyu diperbarui untuk menciptakan dunia virtual yang kemudian diterima sebagai realitas.

\section{Daftar Pustaka}

Eco, Umberto. 1986. Travels in Hyperreality. Orlando, Florida, USA: Harvest/HBJ.

Piliang, Yasraf Amir. 2011. Dunia yang Dilipat: Tamasya Melampaui Batas-batas Kebudayaan. Bandung: Pustaka Matahari

Hall, Stuart. 1997. Representation: Cultural Representation and Signifying Practises, London: Sage Publications

Ricoeur, Paul. 2012. Teori Interpretasi. Yogyakarta: IRCiSoD

Barthes, Roland. 2010. Imaji/ Musik/ Teks: Analisis Semiologi atas Fotografi, Iklan, Film, Musik, Alkitab, Penulisan dan Pembacaan serta Kritik Sastra. Yogyakarta: Jalasutra

Budiman, Kris. 2011. Semiotika Visual: Konsep, Isu, dan Problem Ikonisitas. Yogyakarta: Jalasutra

Scott, John. 2012. Teori Sosial: Masalah-masalah Pokok dalam Sosiologi. Yogyakarta: Pustaka Pelajar

Jones, Pip. 2009. Pengantar Teori-teori Sosial: Dari Teori Fungsionalisme Hingga PostModernisme. Jakarta: Yayasan Pustaka Obor Indonesia

www.filmsite.org/filmgenres.html, diakses tanggal 20 Desember 2013, pukul 01.30 WIB 